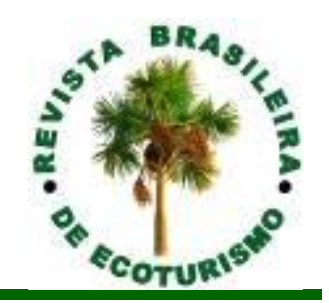

\title{
O turismo de base local e o desenvolvimento territorial do Assentamento 72 em Ladário (MS)
}

\author{
The locally based tourism and territorial development of the \\ settlement 72 in Ladário (MS, Brazil)
}

\author{
Éder Damião Goes Kukiel, Edgar Aparecido da Costa, \\ Milton Augusto Pasquotto Mariani
}

\section{RESUMO}

Este artigo discute as possibilidades de implementação do turismo com base local no Assentamento 72, localizado no município de Ladário, no estado de Mato Grosso do Sul, Brasil, com base nas potencialidades locais e de acordo com os elementos do espaço, propostos por Milton Santos em sua obra "Espaço e Método", de 1985. O turismo é abordado como ferramenta dinamizadora do desenvolvimento territorial rural sustentável, capaz de promover mudanças sociais e econômicas, tendo os camponeses como protagonistas do seu próprio desenvolvimento. Adotou-se como procedimentos metodológicos pesquisa bibliográfica e trabalho de campo. Percebeu-se que o turismo pode ser uma importante alternativa de renda secundária dos camponeses, neste caso, facilitada pela presença de parceiros de reconhecida competência. Contudo, existe uma evidente carência de capacitação do grupo para essa atividade e incremento de infraestrutura, especialmente no que se refere à conservação das estradas.

PALAVRAS-CHAVE: Turismo de Base Local; Desenvolvimento Local; Assentamento 72; Empoderamento; Agricultura Camponesa.

\section{ABSTRACT}

This article discusses the possibilities of implementing tourism locally based in Settlement 72, located in the municipality of Ladário in the state of Mato Grosso do Sul, Brazil, based on local potentials and according to the elements of space, proposed by Milton Santos in his "Espaço e Método" from 1985. The tourism is approached as a dynamic tool for rural sustainable territorial development that promotes social and economic changes, taking peasants as protagonists of their own development. It was adopted as methodological procedures, bibliographic research and fieldwork. It was realized that tourism can be an important alternative for secondary income of peasants, in this case facilitated by the presence of partners of recognized competence. However, there is a clear lack of training for the group considering this activity and infrastructure increasing, especially as regards the maintenance of roads.

KEYWORDS: Locally Based Tourism; Local Development; Settlement 72; Empowerment; Peasant Agriculture. 


\section{Introdução}

O turismo é uma atividade econômica que cresce com grande dinamismo no mundo, se tornando cada vez mais necessário um planejamento eficiente para aproveitar melhor suas virtudes e minimizar alguns impactos negativos que pode produzir nas sociedades locais. Portanto, é indispensável pensar na dimensão social, especialmente nos reflexos para a melhoria de vida das populações dos locais onde se realizam tal atividade (IRVING, 2002).

O turismo em si é uma abstração (CORIOLANO, 2001) e caracteriza-se por ser uma atividade econômica representada pelo conjunto de transações (compra e venda de produtos e serviços turísticos) efetuadas entre os agentes promotores do turismo. É gerado pelo deslocamento voluntário e temporário de pessoas para fora dos limites da área ou região em que têm residência fixa, por qualquer motivo, excetuando-se o exercício de alguma atividade remunerada no local de visita (BRASIL, 1998).

Em outra perspectiva de análise, Barreto (2003) entende que o turismo tem seu crescimento em acordo com a vontade dos grandes capitais internacionais e nacionais, sem grandes preocupações com as consequências para os atores envolvidos nessa atividade. A democratização se torna, portanto, uma saída para que o turismo seja uma atividade agregadora de valores e de inserção social.

Em termos de desenvolvimento territorial rural sustentável, o turismo deve ser articulado com os anseios de comercialização de produtos locais, promovendo tal prática de forma a estabelecer um processo que seja capaz de comprometer minimamente os recursos naturais e humanos, focos do desenvolvimento. É isso que foi pensado numa tentativa de indução de alternativas produtivas para um grupo de camponeses na borda oeste do Pantanal de Mato Grosso do Sul.

Este trabalho originou-se das reflexões advindas da disciplina "Território, Turismo e Desenvolvimento Local", do Mestrado em Estudos Fronteiriços, do Câmpus do Pantanal, da Universidade Federal de Mato Grosso do Sul (UFMS). Além disso, insere-se no contexto das experiências de desenvolvimento local induzidas por pesquisadores da UFMS (Câmpus do Pantanal) e da Embrapa Pantanal no Assentamento 72, em Ladário-MS, a partir de dois projetos de pesquisa: "Alternativas para o desenvolvimento territorial rural do assentamento 72 em Ladário-MS, na região do Pantanal", com apoio do CNPq e, "Sistemas agroecológicos na fronteira Brasil-Bolívia: estudo comparativo das alternativas induzidas no Assentamento 72, em Ladário-MS, com as práticas do assentamento Rosely Nunes, em Mirassol D'Oeste-MT", com recursos do MCT/CNPq e FUNDECT/MS.

De início, esses projetos identificaram os desejos, problemas e potencialidades dos camponeses. Existia uma clara vontade de produzir hortaliças pelo fato do ciclo produtivo ser mais imediato que outras culturas tradicionais, como arroz, milho e feijão e, por haver demanda nas áreas urbanas. A grande dificuldade enfrentada era a carência de água para cultivo, inibindo as práticas agrícolas que, associada à ausência de assistência técnica e precariedade das estradas vicinais que cortam o assentamento, praticamente inviabilizava iniciativas produtivas locais. A mão de obra disponível e o território com solos férteis num meio ecológico de notável beleza paisagística se configuravam como as principais potencialidades do assentamento 72 (COSTA; ZARATE; MACEDO, 2012). 
A partir de então, foram iniciadas ações de capacitação de um grupo de aproximadamente 30 famílias interessadas nas propostas dos pesquisadores. Foram firmadas parcerias com o SEBRAE-MS (Serviço de Apoio às Micro e Pequenas Empresas de Mato Grosso do Sul), via Programa "MS sem fronteiras" e, através desse, com o SENAR (Serviço Nacional de Aprendizagem Rural). A primeira questão foi aproximar os camponeses e fazê-los entender a propriedade como um negócio. Naquele interim, se identificou que os camponeses não sabiam lidar com hortas, apesar da vontade que nutriam de produzi-las, sendo necessário um treinamento específico. Como os projetos de indução do desenvolvimento local tinham também um foco na conservação do ambiente de contato com o Pantanal, simultaneamente ocorreram cursos sobre os fundamentos da agroecologia e preparação de caldas agroecológicas. As caldas são defensivos alternativos cujo preparo se dá através de substâncias que não prejudicam a saúde humana e o ambiente. Ajudam a controlar a ação de vírus, fungos, bactérias e o ataque de pragas nas plantas.

Também foram iniciadas as pesquisas de abelhas nativas sem ferrão e sobre a floração de espécies locais. Foi trabalhada a coesão do grupo, detectada como frágil, buscando desenvolver a capacidade de liderança, enfocando o perfil do líder e o comprometimento em grupo.

O grupo de camponeses foi estimulado e participou de todas as decisões das ações e implementações dos projetos mencionados. Isso se deu por meio de reuniões direcionadas para um determinado fim entre camponeses e pesquisadores. Os participantes ponderavam e, de forma consensual, adotavam estratégias e metas. O monitoramento e a avaliação constantes dos resultados foram produzidos por essa coletividade interativa (camponeses e pesquisadores), implicando na realização de constantes diagnósticos.

Tais induções produziram mudanças sensíveis na paisagem rural, com destaque para as hortas, mas também na mentalidade de algumas famílias que passaram a exigir mais ações das esferas governamentais. É, nesse propósito, que o turismo começa a ser debatido como potencialidade para dinamizar as atividades produtivas locais. O turismo está sendo pensado como uma alternativa, como uma atividade secundária de renda, capaz de abrir canais para agregação de valor na produção local e incrementar a qualidade de vida camponesa.

Portanto, este trabalho se propõe discutir a utilização do turismo de base local como elemento dinamizador do desenvolvimento territorial rural sustentável no Assentamento 72. Especificamente se objetivou identificar o interesse do grupo de camponeses ligados aos projetos de pesquisas mencionados anteriormente em utilizar o turismo como alternativa de renda e propor diretrizes para implementação do turismo de base local no assentamento 72. Para tanto, se buscou a descrição dos elementos do espaço na perspectiva de Santos (1985), a partir da técnica da observação e da pesquisa participante, no âmbito dos projetos de pesquisa mencionados anteriormente. Também foram realizadas dezoito entrevistas com camponeses do Assentamento 72, dentre as vinte e cinco famílias que participam dos projetos, sendo utilizado formulário com perguntas semiestruturadas.

As questões tiveram como propósito entender o conhecimento do grupo de camponeses do assentamento 72 sobre o turismo. Buscou-se conhecer a visão sobre os potenciais a serem explorados, suas dificuldades e os interesses diante de um tema novo para eles. Os elementos levantados foram elaborados na 
concepção do desenvolvimento local, tendo nos camponeses os atores centrais para a explicação das possibilidades de uso do turismo.

Essas alternativas foram encampadas pela Incubadora Tecnológica de Cooperativas Populares do Pantanal e da Fronteira que nasceu em 2014, como iniciativa do mesmo grupo de pesquisadores, no intuito de aprimorar as ações de desenvolvimento desses camponeses. Contudo, esses resultados serão objeto de análises posteriores, cabendo neste trabalho o entendimento dos pressupostos para desenvolvimento do turismo rural como alternativa de renda para 0 assentamento 72 .

\section{Turismo e desenvolvimento local}

O desenvolvimento local passou a ser tratado com mais rigor a partir da década de 1980, influenciado pelas ideias do "ambientalismo" e na crítica sobre o pensamento das políticas de "cima para baixo". De acordo com Zimmerman (1995), o desenvolvimento local passa pelo empoderamento das comunidades como forma de mudanças sociais. Esse processo implica na autonomia do grupo e seu consequente envolvimento nas tomadas de decisões sobre seu cotidiano.

A figura do Estado centralizador, que opera de forma desarticulada das comunidades locais, é criticada por Souza (2001), afirmando sua influência negativa na possibilidade de autonomia de uma sociedade. Para ele, compreender melhor o território é a premissa para se entender as relações que existem no meio rural e promover mudanças qualitativas na vida local.

Zimmerman (1995) indica a existência de três níveis para se caracterizar o processo de empoderamento em determinada localidade: o empoderamento individual ou interpessoal, o organizacional e o comunitário. Na perspectiva deste trabalho, se dará ênfase ao conceito de "empoderamento comunitário", relacionado ao tema estudado e pelo qual, por meio de métodos participativos, a comunidade local cria estratégias e ações para atingir objetivos coletivamente traçados. A busca desses objetivos passa por exaustivas discussões, tensionando as relações de poder, impulsionando conflitos por recursos internos (comunitários) e externos (governamentais, por exemplo).

Cabe ressaltar que esse processo de empoderamento não é imune a obstáculos e dificuldades. A mobilização se torna a chave para transpassar os problemas enfrentados. Comunidades desempoderadas dificilmente se empoderam de forma natural. É necessária a ação de um agente externo, cuja função é articular esse grupo, ou mesmo comunidade, de forma sinérgica, fazendo que se tornem parte de uma rede, onde suas ações tenham vínculos com associações, organizações e movimentos com escalas mais amplas de atuação (PERKINS; ZIMMERMAN, 1995).

Essa visão se aproxima das ações impulsionadas pelos pesquisadores da UFMS e da Embrapa Pantanal no Assentamento 72, quando instituíram a figura dos animadores territoriais (os próprios pesquisadores). Esse personagem foi discutido em Costa, Zarate e Macedo (2012), como sendo um agente que apoia as ações territoriais, que ajuda nas articulações, que elabora projetos, avalia e discute avanços e retrocessos. Essa condição foi necessária para superar a letargia e descrença no próprio futuro que se encontravam aqueles camponeses. 
O animador territorial é constituído no contexto das propostas de desenvolvimento local, que carece de uma "ação de fora" para alavancar um determinado grupo. Vale dizer que o desenvolvimento local tem como base uma comunidade onde, de forma solidária e articulada, possibilita um alargamento das potencialidades econômicas locais, superando a dicotomia rural-urbana, valorizando a diversidade com vistas à sustentabilidade. A gestão social, a participação e engajamento da população local é condição básica para se conseguir esse desenvolvimento (GEHLEN, 2003).

O desenvolvimento local não deve ser entendido fora da perspectiva territorial e do entendimento de território, sob o risco de não se perceber os conflitos inerentes às disputas pelo poder. Para Raffestin (1993), o território é uma construção social que implica no estabelecimento de relações de poder. É, sobretudo, um local de articulação e mediação com o meio externo.

O território é o palco das disputas das associações comunitárias no meio rural que podem ser vislumbradas nas tensões e relações de poder desde sua origem, funcionamento, na escolha de seus representantes. Nesse sentido, o território é produzido espaço-temporalmente, se efetivando em diferentes escalas, de forma permanente ou temporária (CANDIOTTO, 2004).

O território pode ainda ser identificado, de acordo com seu processo de formação, em quatro categorias: o território cotidiano, das trocas, de referência e do sagrado (RAFFESTIN, 1993). No assentamento rural estudado são mais perceptíveis os territórios do cotidiano e das trocas. O primeiro se refere às características de descontinuidade: é o território imediato onde ocorrem as relações do dia a dia. Refere-se a "[...] um espaço onde se projetou um trabalho, seja energia e informação, e que, por consequência, revela relações marcadas pelo poder" (RAFFESTIN, 1993, p.144). O segundo diz respeito a fluidez e movimento constante: remete à circulação de mercadorias em escala local, regional e global.

Para Gottmann (1973), o território é organizado de forma a atender as necessidades dos agentes humanos existindo uma relação de domínio e de controle, sempre enraizados por questões de caráter político, ideológico e econômico.

De acordo com Carneiro (1998), o rural não se define somente pela atividade agrícola. Também vem sendo ampliadas as atividades não agrícolas, resultando num caráter de pluriatividade. Surgem, portanto, novas formas de arranjos territoriais capazes de promover uma reorientação da capacidade produtiva ou mesmo meios alternativos de vida no campo. Nesse sentido, o desafio é aliar o cotidiano com a cultura local para impulsionar o desenvolvimento.

Na mesma linha de pensamento, Campanhola e Graziano da Silva (2000) apontam uma transformação multifuncional ocorrendo no meio rural. Além das atividades convencionais ligadas a agricultura existe outras como: lazer, turismo, conservação de ecossistemas, agricultura ecológica, educação ambiental entre outros.

Mendonça (2004), por exemplo, analisou a experiência de turismo de base local na Prainha do Canto Verde, no município de Beberibe, estado do Ceará, Brasil, focalizando as mudanças que essa comunidade passou durante a introdução da atividade turística, como forma de melhoria de renda e inserção social. Trata-se de uma comunidade originada de imigrantes, que buscavam terras 
para habitar e alternativas para a sobrevivência, encontradas especialmente na pesca. Desde sua formação foram enfrentados inúmeros conflitos pela posse e uso da terra. Por se tratar um lugar de grande beleza e exuberância da paisagem, os grileiros locais desejavam tomá-lo para fins imobiliários, tornando-se os principais competidores por essas terras.

A principal atividade econômica de Prainha do Canto Verde é a pesca, consumida localmente e utilizada em permutas por alimentos, como farinha e feijão e com os excedentes comercializados em localidades próximas. O turismo apareceu como uma oportunidade de geração de emprego e renda complementar, criando novas possibilidades, como a função de guias, bugreiros e cozinheiros etc. Igualmente foram estimuladas outras atividades, como a produção de artesanato, pintura, trabalho na pousada comunitária e fomento aos pequenos produtores locais. O risco era despertar os interesses dos agentes imobiliários (MENDONÇA, 2004).

Em trabalho posterior, Mendonça, Moraes e Costa (2013) observam que as preocupações dos nativos com a venda das terras e imposição de agentes imobiliários estavam acertadas. Ocorreram várias formas de pressão para tomadas das terras dos nativos, inclusive via usucapião. A alternativa foi tornar a área de uso (mar e terra) como Resex, a Reserva Extrativista da Prainha de Canto Verde, oficializada em 05/06/2009. Essa medida não foi suficiente, pois um empresário que busca comprar terras na localidade estimulou a secção da associação. Assim, em 2012, foi criada a Associação Independente da Prainha de Canto Verde e Adjacências (AIMPCVA) que questiona a Resex em terra firme e a dificuldade dos nativos fazerem reformas e sua impossibilidade de vender as casas.

A partir do trabalho de Mendonça (2004), depreende-se que a introdução da atividade turística em Prainha do Canto Verde resultou nos seguintes pontos positivos: geração de postos de trabalho e renda, ampliação da venda do pescado, valorização do artesanato local e melhoria na infraestrutura, como de educação e do sistema de saúde. Esses resultados demonstram que o processo de participação se torna um importante instrumento de desenvolvimento, desde que planejado e executado com liberdade. O turismo pode ser uma alternativa de renda, apoiando na melhoria da qualidade de vida e na inserção social, desde que seja utilizada de forma sustentável e com forte base comunitária. Entretanto, o trabalho de Mendonça, Moraes e Costa (2013) indica a necessidade de o grupo estar atento a todas as transformações no entorno e em seu próprio interior de modo a evitar a própria desterritorialização.

\section{Potencialidades de turismo no assentamento 72}

O assentamento 72 está localizado na borda oeste do Pantanal, no estado de Mato Grosso do Sul, na porção Oeste do Brasil, a $7 \mathrm{~km}$ da área urbana do município de Ladário-MS (Figura 1). Foi criado em 1999, pelo Instituto Nacional de Colonização e Reforma Agrária - INCRA, a partir da Fazenda Primavera e, conta com área de 2.341,2996 ha, em 85 unidades rurais familiares, com tamanho médio de 18,5 ha (COSTA, ZARATE e MACEDO, 2012). 


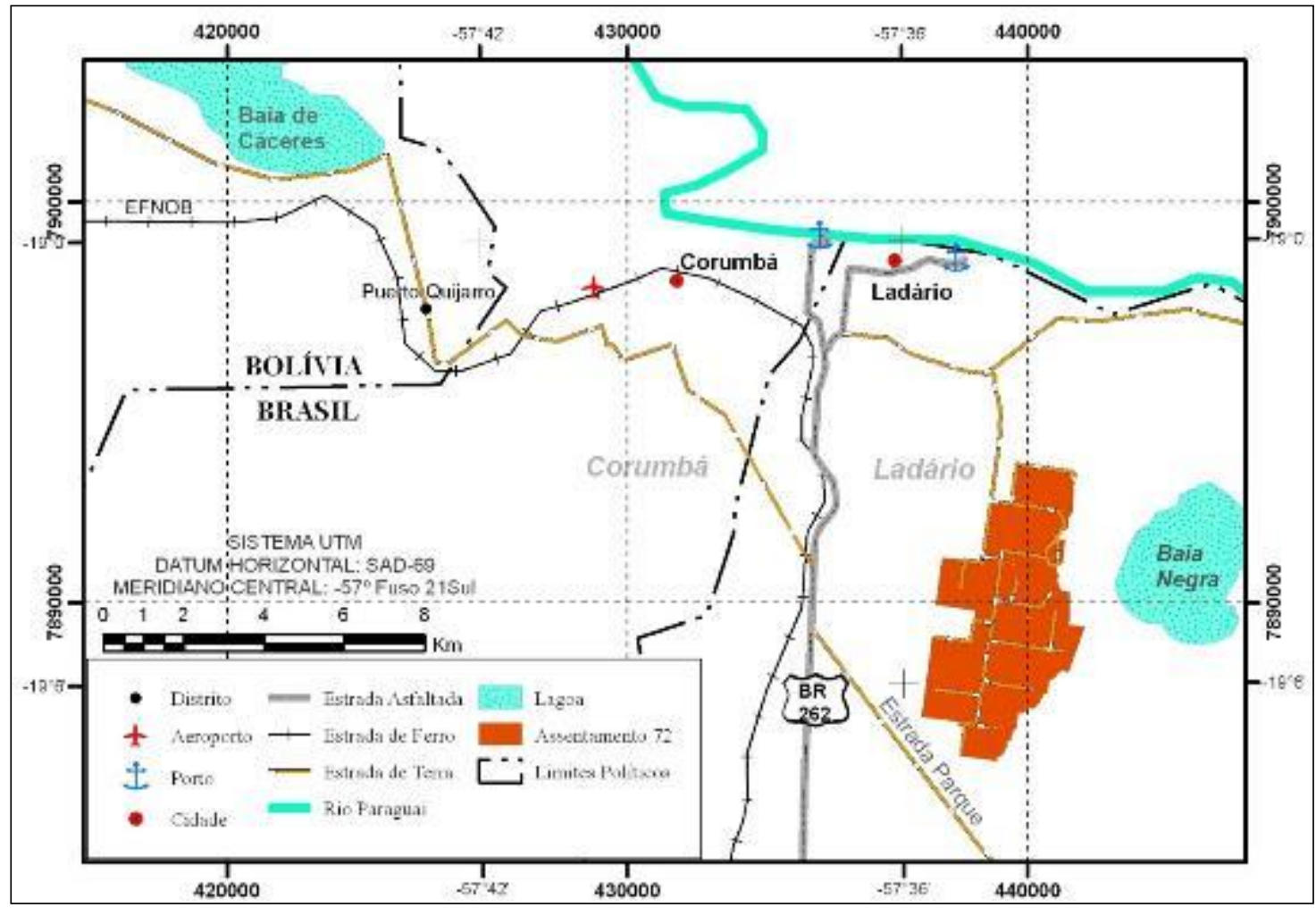

Figura 1: Localização do Assentamento 72, Ladário (MS).

Figure 1: Settling location 72, Ladário (MS).

Fonte: Costa, Zarate e Macedo (2012, p.128).

Source: Costa, Zarate and Macedo (2012, p.128).

Optou-se por discutir as potencialidades turísticas do Assentamento 72, a seguir, a partir dos elementos do espaço, propostos por Milton Santos (1985), em sua obra "Espaço e Método". Partiu-se do entendimento de que a obra se tornou uma facilitadora da análise geográfica e se desejou refletir se ainda se mostra viável. Santos (1985) considera cinco elementos: os homens, as firmas, as instituições, o meio ecológico e as infraestruturas. Esses elementos são intercambiáveis e variáveis em relação à função, forma e posição no território, de acordo com o momento histórico vivido. Muitas vezes é impossível separá-los e, nesse sentido, a discussão e apresentação de uma variável poderia muito bem estar localizada em outro elemento. Entretanto, a partir da experimentação da localidade, das atividades vinculadas aos projetos desenvolvidos, optou-se pela formatação apresentada a seguir, em conformidade com o esquema trabalhado por Figueiredo, Costa e Paula (2011).

Apesar de ser uma obra de 1985, a proposta de análise dos elementos do espaço feita por Milton Santos ainda se mostrou passível de ser utilizada. Logicamente carece de ajustes de interpretação em razão das dinâmicas socioterritoriais da atualidade, minimizada pela lógica da totalidade sugerida como fio condutor de sua proposição. Por outro lado, o uso do termo homem se mostra fora do contexto atual e padece de atualização. Em nossa opinião, a maior virtude desta abordagem é sua aplicabilidade para estudos na escala local, como as relativas ao turismo de base comunitária. Talvez, a maior dificuldade de uso seja para os estudos com maior complexidade dos relacionamentos e das articulações entre as escalas local, regional, nacional e internacional. 


\section{Os homens}

Para Santos (1985), os homens são elementos que compõem o espaço, cuja função é fornecer trabalho ou, pelo menos estar apto a candidatar-se a exercer tal função. No caso do assentamento 72 , se pode observar que os homens são os camponeses e as camponesas que residem no lugar, as pessoas que prestam serviços no assentamento, os pesquisadores e os visitantes em geral. Como se pode observar, esse elemento poderia ser denominado de homens e mulheres ou de seres humanos. Contudo, se perderia a originalidade do termo empregado por Santos (1985).

São 85 famílias assentadas que, segundo Costa, Zarate e Macedo (2012), perfazem uma população residente de quase 280 pessoas, com média de 3,2 pessoas por moradia. A maioria é masculina (57,5\%), explicada pela quantidade de lotes com uma só pessoa (19 lotes, muitas vezes um caseiro). Grande parte delas sempre morou na zona rural (64\%), e mais da metade, na própria região: Corumbá e Ladário (incluindo os pantanais da Nhecolândia, do Paiaguás e os ribeirinhos em geral). Quase 60\% da população são adultos (entre 20 e 60 anos), 37\% são jovens e pouco menos que 13\% são idosos (mais de 60 anos).

Costa, Zarate e Macedo (2012) identificaram, quanto ao nível de escolaridade, $45 \%$ das pessoas com formação até as séries iniciais ( $1^{\text {a }}$ a $5^{\text {a }}$ série da Educação Básica), 13,50\% de pessoas analfabetas e menos de 5\% com nível superior completo ou incompleto (os demais com formação entre a $6^{\underline{a}}$ e a $9^{\underline{a}}$ série ou com nível médio).

As mulheres participam de dupla jornada de trabalho, cuidando dos afazeres domésticos e das atividades agrícolas, especialmente das roças, juntamente com seus maridos e filhos (quando não estão na escola). Ainda não se organizaram num grupo de trabalho, apesar de ser um dos objetivos dos pesquisadores que atuam no assentamento. Vale ressaltar que na localidade existe uma cultura de participação do casal em todas as atividades: reuniões, capacitações, fabricação de doces caseiros, trabalho na horta, dentre outros.

Os professores são difusores de saberes no âmbito da escola, que se localiza no assentamento (abordada mais adiante). Contudo, nenhum deles reside no local, mas nas áreas urbanas de Ladário ou Corumbá. São potenciais agentes de apoio na educação ambiental e de turismo rural sustentável, apesar de carecerem de capacitação para tal proposta. Também estão presentes no espaço, os médicos e dentistas (autóctones), que fazem atendimento básico, e um agente de saúde, que reside no assentamento.

Os pesquisadores da UFMS e da Embrapa Pantanal são fundamentais como articuladores entre os interesses dos camponeses e as instituições. Estão presentes no assentamento durante suas pesquisas e oferecem cursos de capacitação e alternativas para melhorar o trato com a terra através de novas técnicas de cultivo. Podem apoiar, ainda, na construção de um modelo sustentável de turismo rural.

Os funcionários da Prefeitura Municipal de Ladário comparecem, frequentemente, no assentamento e são importantes elos de apoio e melhoria da infraestrutura local. Outros visitantes (compradores diretos, atravessadores, pessoas que vão conhecer as práticas agrícolas induzidas pelos pesquisadores da 
Embrapa Pantanal e da UFMS, dentre outros) e turistas (esses menos frequentes) são disseminadores das características locais para fora do assentamento.

Portanto, os homens e as mulheres são potenciais de desenvolvimento do turismo, já que sua própria forma de relação particular com o meio os tornam em atrativos. No mesmo sentido, os vários cursos realizados produzem uma condição de nivelamento de base para implementação de uma nova atividade econômica. Ademais, os agentes exógenos que atuam no assentamento podem colaborar na elaboração de uma proposta de alternativas de renda participativa, agregando e potencializando os saberes locais.

\section{As firmas}

De acordo com Santos (1985), as firmas têm como função principal a produção de bens, serviços e ideias. No assentamento 72 as firmas atuam como elementos exógenos e são compradoras/oferecedoras de emprego e produtos ou vendedoras para os camponeses. No primeiro caso, tem-se, diretamente, a empresa de mineração Vale (que emprega membros das famílias do assentamento); sua contratada para prestação de serviços, a Newrest do Brasil (um conglomerado francês que atua na área de alimentação coletiva) que fornece refeições para os funcionários da Vale, comprando verduras do assentamento e; o supermercado Barateiro, que compra verduras do local para vender em seu estabelecimento comercial. No segundo caso, estão os supermercados, farmácias, escritórios de diversos fins, casas agropecuárias, de materiais de construção civil, de insumos agrícolas, dentre outras, localizadas nas cidades de Ladário, de Corumbá e também as do lado boliviano da fronteira, que vendem produtos para os camponeses.

A empresa de mineração Vale, que possui minas de extração de minério de ferro e manganês em Corumbá e Ladário, também investe recursos para apoio aos camponeses, desde que se tenha um projeto, na forma de compensação ambiental. Mediante articulação com pesquisadores da UFMS e Embrapa Pantanal apoiou a perfuração de poços artesianos, garantindo água para a produção de verduras em três lotes. Torna-se uma potencialidade no apoio de projetos estruturantes na direção sustentável para a localidade.

Os relacionamentos dos camponeses com as firmas para a venda de seus produtos (como hortaliças, leite, queijo e doces caseiros), além de ampliar sua renda, introduz novos conceitos, como o atendimento aos prazos estabelecidos e os cuidados com a qualidade dos produtos ofertados - tanto na manipulação, como na embalagem e transporte -, dentre outros. As firmas são elementos de grande relevância na construção de alternativas de produção local, já que as principais áreas produtoras de alimentos estão consideravelmente distantes - mais de 300 km de Corumbá e Ladário.

\section{As Instituições}

Segundo Santos (1985), as instituições produzem normas, ordens e legitimações, podendo se tonar de grande ajuda para os camponeses, em razão do conhecimento científico, fato que já pode ser comprovado pelas atividades promovidas pelas mesmas nessa comunidade e, igualmente, por sua capacidade de articulação para além da escala local. 
O Estado se faz presente na comunidade do 72 nas três esferas de governo, com intensidade desigual das ações executadas. Na escala local, através da Prefeitura e suas secretarias, cuidando das estradas de acesso, da saúde, da educação básica e outras formas de apoio, especialmente à produção (doação de óleo diesel para o trator da associação, por exemplo). Trata-se de um agente com capacidade de criar condições e gerar infraestrutura para que se realize turismo com base local, melhorando as estruturas já existentes e fornecendo ou apoiando em outras necessidades. Possui, ainda, a competência de articulação para a realização de eventos locais capazes de atrair um público novo para o consumo de produtos e também na promoção de eventos e na publicidade de um turismo alternativo local.

Além do alcance das legislações, a esfera estadual materializa sua presença da AGRAER (Agência de Desenvolvimento Agrário e Extensão Rural), que tem como objetivos fomentar $e$ incentivar 0 associativismo como forma de fortalecimento das comunidades, além de acompanhar e assessorar projetos ligados a assentamentos rurais. No assentamento 72 sua atuação tem se restringido a emitir a Declaração de Aptidão ao Pronaf (DAP), necessária para o agricultor familiar fornecer à alimentação escolar e acessar créditos na qualidade de pequeno produtor rural.

A esfera federal tem no INCRA (Instituto Nacional de Colonização e Reforma Agrária) seu principal representante. Esse agente é o responsável pela criação do assentamento e, até os dias atuais, o mantém sob seu controle, já que ainda não foi consolidado. Os camponeses do 72 tem travado uma luta com esse órgão para viabilização de água suficiente para consumo e produção agrícola, já que essa é uma das principais carências da localidade.

Além dessas, existem várias outras instituições de ensino superior, pesquisa e de apoio aos agricultores que atuam no assentamento. A Universidade Federal de Mato Grosso do Sul vem atuando com propostas de desenvolvimento local e consequente apoio das demandas locais. Possui grande potencial, pelo conhecimento científico e pela capacidade de articulação com outras instituições para propor o turismo de forma sustentável, minimizando impactos culturais e ambientais e maximizando os ganhos econômicos.

A Embrapa Pantanal (Empresa Brasileira de Pesquisa Agropecuária) vem desenvolvendo importante trabalho de indução de mudança de concepção produtiva no assentamento 72 , a ponto de várias famílias já se encontrarem em estágio de transição agroecológica. Também, através de projetos de pesquisa, vem desempenhando o papel de extensão rural, negligenciado pelas instituições estaduais e municipais do setor. Essa instituição, da mesma forma que a UFMS, tem grande potencial como parceira na execução de projetos de turismo sustentável.

O Sebrae (Serviço Brasileiro de Apoio às Micro e Pequenas Empresas em Mato Grosso do Sul) vem atuando no assentamento 72 desde início de 2011, em parceria com a UFMS câmpus do Pantanal, via Acordo de Cooperação no projeto de pesquisa "Alternativas para o desenvolvimento territorial rural do assentamento 72 em Ladário-MS, na região do Pantanal", através do Programa "MS sem fronteiras". Nessa parceria já foram oferecidos, gratuitamente aos camponeses, os seguintes cursos: "Negócio Certo Rural", "Juntos somos fortes", "Metodologia de Resolução de Problemas" e "Associativismo e cooperativismo". O Sebrae tem 
articulações na escala nacional, podendo viabilizar a capacitação de grupos nas mais diversas vocações de inovação e empreendedorismo, inclusive relacionadas ao turismo rural.

O SENAR (Serviço Nacional de Aprendizagem Rural) tem como objetivo principal realizar a formação profissional no meio rural e a promoção social de jovens e adultos que exercem atividades dessa natureza. Oferece assistência aos pequenos produtores difundindo novos métodos de produção sustentável, visando assegurar sua permanência no campo. Essa instituição já atua na comunidade do 72, participando ativamente no processo de desenvolvimento local em parceria entre a Universidade Federal do Mato Grosso do Sul, Sebrae/MS, Embrapa Pantanal e Associação dos Pequenos Produtores Rurais do Assentamento 72, promovendo cursos de capacitação para melhoria da relação dos assentados com a terra e com o mercado externo. Um exemplo disso foi o curso "Manejo de hortas", oferecido em meados de 2011, gratuitamente.

A Associação dos Pequenos Produtores Rurais do Assentamento 72, até então, se apresenta como uma grande potencialidade, apesar da fragilidade de articulação interna, especialmente provocada pela desconfiança da comunidade em suas lideranças. Os camponeses parecem entender muito pouco a capacidade de articulação territorial de uma associação de produtores rurais, inclusive de buscar recursos em prol da coletividade, ou grupos específicos. Desde sua criação, a associação tem se preocupado em resolver problemas relacionados à melhoria das condições das estradas do assentamento, com o abastecimento de água, fornecimento de energia, regularização junto ao INCRA e busca por assistência técnica. Apesar dos cursos de capacitação, ainda falta o entendimento do verdadeiro sentido de uma associação ligada à produção rural. De todo modo, a aproximação com as demais instituições retro mencionadas tem permitido que a associação permaneça regular, apta para captação e recebimento de recursos para investimento.

O Sindicato dos Trabalhadores Rurais de Ladário teve uma função muito importante ao buscar a UFMS para apoiar as iniciativas do assentamento, aproximando, também, a associação local. Contudo, atualmente, com a mudança de gestão, se mantém restrita a questões burocráticas. Entretanto, é importante elo de mobilização camponesa e de possibilidades de articulações territoriais em diversas escalas.

A Marinha do Brasil, através do 6ํㅡㄹ Distrito Naval (6DN), com sede em Ladário, é outra importante instituição que atua no assentamento, através de compras de hortaliças, via Programa de Aquisição de Alimentos - PAA - que é um instrumento para fortalecimento da agricultura familiar. Além disso, em 2013, o 6DN abriu uma feira livre para os camponeses do 72 comercializarem sua produção na vila militar, sem concorrência com demais produtores.

\section{A infraestrutura}

As infraestruturas, para Santos (1985), são o trabalho humano materializado e espacializado na forma de casas, plantações, caminhos. São construções, materialidades que se misturam intensamente com o meio ecológico confundindose, por vezes, como um só elemento. Para efeito deste trabalho será considerado infraestrutura toda intervenção humana para viabilizar atividades socioeconômicas, que incorpora o meio ecológico dotando-o da racionalidade de seu tempo histórico. 
A infraestrutura se configura como a maior dificuldade para a realização de um turismo sustentável no assentamento 72, carecendo de investimentos, mas não inviabilizando sua possibilidade. As estradas que dão acesso ao local, bem como os travessões de ligação interna, se apresentam em más condições para uso, piorando consideravelmente no período de chuvas. Na época de seca, os buracos e a poeira são os principais agravantes. Soma-se a isso a falta de sinalização. Contudo, havendo uma proposição compartilhada entre instituições e empresas é plenamente possível a manutenção da qualidade dessas vias de transporte.

Em geral, as casas são de tamanho modesto e de alvenaria. As benfeitorias são variáveis de lote para lote. A maioria possui curral para bovinos e ou ovinos e galpões. Todos os lotes, que variam entre 15 a 24 hectares de terra, são cercados com arame farpado ou liso.

A rede de água que abastece o assentamento vem de duas fontes principais: de um poço semiartesiano próximo ao córrego Banda Alta, que atende à maioria dos lotes, e de outro poço, localizado no lote 37, que fornece água para 25 lotes. Foi construída pelo INCRA quando da entrega dos lotes. Não se paga conta de água e, sim, de energia, rateada entre todos os assentados. Essa água não é suficiente para as atividades produtivas ligadas à agricultura e por vezes ocorre 0 corte no abastecimento em razão do não pagamento das taxas de energia (COSTA, 2014).

A rede de energia distribuída aos lotes é monofásica, não permitindo a existência de estruturas que demandem de energia mais potente. Quando necessário, individualmente, os camponeses acertam com a empresa concessionária a instalação de um padrão bifásico. É assim que funcionam os poços artesianos, construídos por iniciativa particular ou pelos projetos de pesquisa intervencionista.

As hortas para produção de verduras são construídas com a utilização de telas de arame, sombrite (por causa das elevadas temperaturas e fortes incidências dos raios solares), áreas para produção de mudas e os canteiros (Figura 2). Com produção sem uso de agrotóxicos tornam-se importantes infraestruturas/atividades agrícolas para atrair o interesse de turistas. Existem 5 propriedades com produção hortícola em escala comercial e outras 15 que vendem apenas os excedentes produtivos.

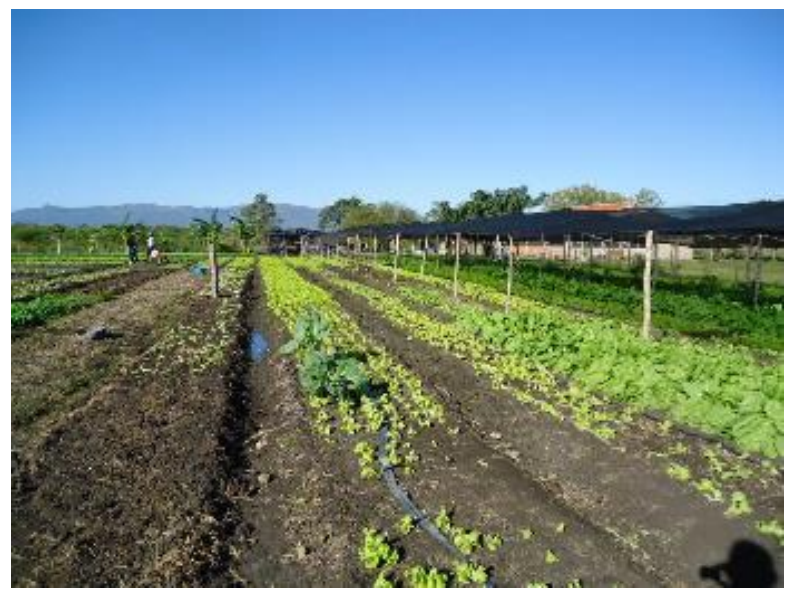

Figura 2: Horta modelo no lote 18, assentamento 72, Ladário (MS, Brasil).

Figure 2: Plantation model in Lot 18, laying 72, Ladário (MS, Brazil).

Autor: Costa (2013).

Author: Costa (2013). 
O assentamento 72 possui um Centro de Atendimento Múltiplo, onde funciona um espaço para atendimento médico e odontológico (uma vez por semana); uma escola rural, que atende do $1^{\circ}$ a $5^{\circ}$ ano do ensino fundamental, com um total de 6 professores; uma sala de computadores; biblioteca; um campo de futebol, em condições precárias; uma construção abandonada (que seria um ponto de recebimento e resfriadouro do leite); além de ampla área passível de ser ocupada por outras edificações.

Do ponto de vista das condições de acesso do turista a partir da rede aeroviária regional, a localidade tem sua articulação a partir do Aeroporto Internacional de Corumbá. Desde agosto de 2015 a companhia aérea que fazia o trecho Corumbá-Campo Grande passou a operar voos CampinasCorumbá/Corumbá-Campinas quatro vezes por semana (segundas, quartas, sextas-feiras e domingos). A empresa opera com capacidade para 106 passageiros. Neste sentido, uma possível demanda turística pode acessar a localidade a partir dos principais centros emissores nacionais.

A conexão com a capital do Estado de Mato Grosso do Sul, Campo Grande, ocorre pela BR 262, rodovia federal asfaltada com extensão (nesse trecho) de 430 $\mathrm{km}$. O acesso é facilitado pela existência de linha regular de ônibus com 8 linhas diárias. A partir dali é possível estabelecer conexões com várias partes do mundo.

A entrada de turistas, também, pode ocorrer a partir da Bolívia. O Aeroporto Internacional Salvador Ogaya Gutiérrez, em Puerto Suárez, à 30 km da localidade, estabelece conexões com Santa Cruz de la Sierra que se articula amplamente com a rede mundial de aeroportos. A ligação entre a fronteira e aquela cidade ocorre, ainda, pelas vias ferroviária e rodoviária.

\section{O meio ecológico}

De acordo com Milton Santos (1985), o meio ecológico corresponde ao conjunto de complexos territoriais que constituem a base física do trabalho humano, neste caso, uma das maiores potencialidades do Assentamento 72, que se localiza no contexto do Pantanal Sul-mato-grossense.

Costa, Zarate e Macedo (2012) descrevem que a geologia local é formada por rochas muito antigas do Pré-Cambriano Superior, que deram origem a formações detríticas pleistocênicas que dominam a área do assentamento. O relevo é plano, com declives inferiores a $3^{\circ}$ e altitude média de 100 metros em relação ao nível médio do mar. Os solos são pouco profundos (espessura máxima de $1 \mathrm{~m}$ ), escuros, originados de rochas calcárias, com argila de atividade alta, podendo expandir-se ou contrair-se de acordo com a variação da umidade, tornando-se muito duros nos períodos secos e encharcados nos períodos úmidos. Possui boa aptidão para práticas agrícolas, considerando o tipo de manejo "A" (baixo uso tecnológico), e regular no tipo de manejo "B" (para médio uso de tecnologia). Os recursos hídricos superficiais são escassos e sazonais, restritos ao córrego Banda Alta, a noroeste do assentamento e um prolongamento da Baía Negra, a leste.

A fauna e a flora diversas se apresentam como grandes potencialidades, podendo ser usadas como forma de atração aos visitantes. A fauna é composta por diversas aves e animais silvestres como a queixada, veados, tatus, capivaras, onças e antas. A flora se apresenta com grande diversidade, com destaque para floresta tropical subcaducifólia e caducifólia (MATO GROSSO DO SUL, 2008), nas 
áreas livres de inundação, destacando-se árvores nativas da região como angico, aroeira entre outros. Nas áreas mais baixas propensas a inundação observa-se a presença de bosque chaquenho e bosque de carandá, planta típica da região (MATO GROSSO DO SUL, 2008). Existe, também, uma reserva legal que se distribui por quatro blocos dentro do assentamento 72. Ela se encontra protegida e engloba a mata ciliar do Córrego Banda Alta.

A paisagem marcada pela presença de morrarias na porção meridional constitui-se um elemento natural para contemplação. Nesse conjunto paisagístico, a Baía Negra representa o principal potencial a ser explorado turisticamente. Existem inúmeras possibilidades a partir dos lotes que estão em seu contato, especialmente do lote 01 (Figura 3). Nele, pela declividade, é possível construir uma tirolesa, organizar passeios contemplativos de barcos, pesque e solte, trilhas ecológicas, dentre outros. A localidade apresenta condições de abrigar uma pousada, lanchonete, ou mesmo um restaurante do tipo Quilômetro Zero, com funcionamento sazonal, ofertando apenas alimentos produzidos no lote ou das proximidades.

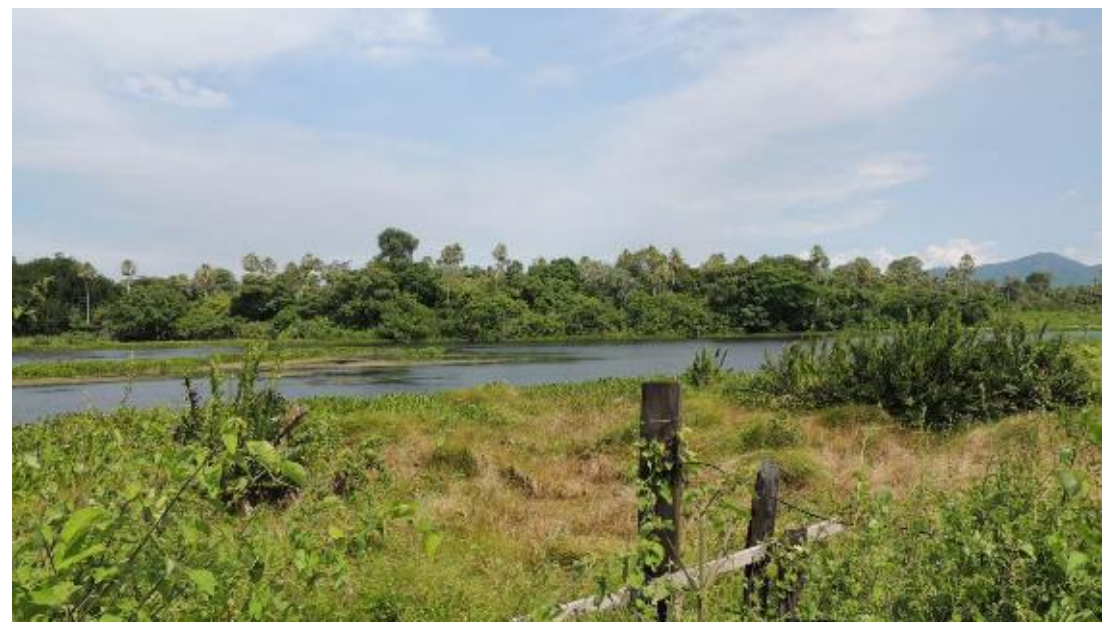

Figura 3: Vista para a Baia Negra a partir do lote 01, assentamento 72, Ladário (MS, Brasil). Figure 3: View Baia Negra from Lot 01, seating 72, Ladário (MS, Brazil)

Autor: Costa (2013).

Author: Costa (2013).

Vale lembrar que os restaurantes do tipo KM Zero ou Zero Quilômetro são aqueles nos quais todos os ingredientes viajam as menores distâncias possíveis (PROENÇA, 2010). Neste caso, o ideal seria que a família conseguisse produzir a maioria dos alimentos a serem oferecidos aos clientes, complementando com a produção dos camponeses vizinhos. Pugliesi e Cunha (2014) indicam que a distância máxima para o deslocamento dos alimentos do local da produção até esse tipo de restaurante deve ser $20 \mathrm{~km}$. Acreditamos que para a realidade local não deve ultrapassar $5 \mathrm{~km}$ sob o risco de se perder a identidade territorial.

\section{Diretrizes para a implementação de turismo de base local no assentamento 72}

Com o objetivo de conhecer a percepção que o grupo de camponeses do Assentamento 72, que participam projeto de alternativas para o desenvolvimento territorial rural, tinha em relação à atividade do turismo foi realizada uma pesquisa com as 18 famílias, em março de 2013. Essa pesquisa ocorreu durante uma reunião 
participativa no lote 35 para avaliar os resultados da experimentação da adubação verde (adição de leguminosas na superfície do solo para seu enriquecimento). Utilizou-se um formulário semiestruturado que foi aplicado pelos acadêmicos bolsistas dos projetos de pesquisa, com duração média de sete minutos, de forma individual ou com o casal. As respostas foram anotadas nos formulários para posterior análise e sistematização. De acordo com as respostas obtidas foi possível perceber que eles possuem conhecimento limitado em relação à atividade do turismo e suas potencialidades. O turismo é entendido como 0 ato de se realizar uma visitação, ou mesmo uma contemplação.

Apesar do pouco conhecimento demonstrado em relação ao turismo, todos os entrevistados se mostraram entusiasmados em trabalhar com essa atividade em seus lotes e a colaborar nos projetos com esse foco. Embora reclamem a falta de estrutura em seus lotes como elemento inibidor dessa atividade, afirmam a disposição em buscar formas de financiamento, para melhor adequar seus espaços à prática do turismo. Também se mostraram propensos a realizarem cursos de capacitação para atender e receber os turistas.

Quando perguntados em relação às potencialidades que o assentamento apresenta para a atração de turistas, elencaram: a paisagem, as festas locais, as comidas típicas, o cotidiano rural (a lida com o gado bovino, o trato da horta, a preparação dos doces caseiros, dentre outros afazeres) e os produtos que poderiam ser comercializados aos visitantes (doces, artesanatos). De fato, existem vários pontos que podem ser catalogados para observação da morraria Urucum, da Baía Negra, da paisagem cultural construída pelos camponeses, dentre outras. Não existe uma especificidade de comidas típicas da localidade, até porque não se trata de uma comunidade com tradição secular no mesmo ambiente. Destacam-se as comidas próprias do meio rural composta por arroz, feijão, salada, macarrão, mandioca, abóbora, quiabo e o tradicional churrasco feito no chão, especialmente servido durante alguma festividade.

Outro resultado apontado pela pesquisa mostra que a comunidade entende que a geração de trabalho e possibilidade do aumento da renda sejam os principais benefícios a serem trazidos pelo turismo para dentro do espaço rural. Não são conhecidas por eles outras experimentações de turismo comunitário, para efeitos comparativos. Observam a necessidade de melhoria da infraestrutura, principalmente as estradas e acessos ao assentamento, para melhor receber os turistas.

Assim, tendo por base a discussão teórica sobre o turismo de base local, um olhar sobre os elementos do espaço do assentamento 72 e o entendimento dos entrevistados sobre a atividade turística é possível pensar algumas proposições (Quadro 1). 
Quadro 1: Diretrizes para implementação do turismo de base local no assentamento 72, Ladário (MS). Table 1: Guidelines for implementation of locally based tourism in the settlement 72, Ladário (MS, Brazil).

Fonte: Elaboração própria (2014).

Source: Authors (2014).

\begin{tabular}{|c|c|c|c|}
\hline Diretriz & Ação & $\begin{array}{c}\text { Atores sociais } \\
\text { envolvidos }\end{array}$ & $\begin{array}{l}\text { Recursos } \\
\text { disponíveis }\end{array}$ \\
\hline $\begin{array}{l}\text { Dotar o lote } 01 \text { de } \\
\text { infraestrutura para } \\
\text { tirolesa, camping e } \\
\text { restaurante do tipo } \\
\text { "Quilômetro Zero". }\end{array}$ & $\begin{array}{l}\text { Busca de parceiros para } \\
\text { os empreendimentos, } \\
\text { capacitação dos } \\
\text { camponeses para } \\
\text { atendimento de turistas. }\end{array}$ & $\begin{array}{l}\text { Prefeitura, UFMS, } \\
\text { SEBRAE/MS, } \\
\text { Embrapa Pantanal, } \\
\text { Governo do Estado. }\end{array}$ & $\begin{array}{l}\text { Editais do CNPq, } \\
\text { Ministério do } \\
\text { Turismo, parcerias } \\
\text { com empresas. }\end{array}$ \\
\hline $\begin{array}{l}\text { Elaborar um roteiro da } \\
\text { produção agroecológica } \\
\text { e de doces caseiros do } \\
\text { assentamento } 72 .\end{array}$ & $\begin{array}{c}\text { Construção de roteiro } \\
\text { turístico agroecológico, } \\
\text { identificação e sinalização } \\
\text { dos lotes com produção } \\
\text { agroecológica. }\end{array}$ & $\begin{array}{c}\text { UFMS, Embrapa } \\
\text { Pantanal, Sebrae/MS } \\
\text { e Associação local. }\end{array}$ & $\begin{array}{c}\text { Editais do CNPq, } \\
\text { Sebrae/MS. }\end{array}$ \\
\hline $\begin{array}{l}\text { Identificar os lotes com } \\
\text { capacidade e interesse } \\
\text { para oferecer } \\
\text { hospedagem e } \\
\text { alimentação aos } \\
\text { turistas. }\end{array}$ & $\begin{array}{l}\text { Levantamento de } \\
\text { interesse dos } \\
\text { camponeses, } \\
\text { discriminação de } \\
\text { possíveis leitos e } \\
\text { cardápios. }\end{array}$ & $\begin{array}{l}\text { Prefeitura, UFMS, } \\
\text { SEBRAE/MS, } \\
\text { Embrapa Pantanal, } \\
\text { Governo do Estado. }\end{array}$ & $\begin{array}{l}\text { Editais do CNPq, } \\
\text { Ministério do } \\
\text { Turismo, parcerias } \\
\text { com empresas. }\end{array}$ \\
\hline $\begin{array}{c}\text { Melhorar a } \\
\text { infraestrutura de acesso } \\
\text { ao assentamento. }\end{array}$ & $\begin{array}{c}\text { Recuperação das } \\
\text { estradas vicinais internas } \\
\text { e as que ligam o } \\
\text { assentamento à cidade. }\end{array}$ & Prefeitura. & Prefeitura. \\
\hline
\end{tabular}

A exemplo do que aconteceu em Prainha do Canto Verde é fundamental estar atento aos possíveis impactos que a atividade turística pode gerar no território estudado. Os modos de vida dos camponeses e das camponesas podem ser significativamente alterados pela intensificação de dedicação às atividades turísticas, como bem alertou Schneider (2006). O autor aponta cinco cuidados importantes na indução de atividades turísticas para agricultores familiares: a) o respeito às relações sociais e produtivas previamente existentes; b) o conhecimento da natureza social referente à construção dos mercados e o posicionamento dos camponeses nas relações de troca em razão de suas raízes socioculturais; c) não encará-las como a "salvação da lavoura", pois, não promovem a inclusão de todas as famílias e unidades produtivas, estão sujeitas à sazonalidade e podem aumentar a jornada de trabalho, principalmente das mulheres, além de reduzir a privacidade da família; d) pensá-las na perspectiva da pluriatividade das famílias, ou seja, num caráter complementar às atividades agrícolas; e) prever o envolvimento de todos os atores interessados nas atividades ligadas ao turismo rural, elaborando mecanismos de responsabilização social e de institucionalização, de forma a evitar o clientelismo e a dominação.

Nesse sentido, um turismo comprometido com o desenvolvimento das localidades é aquele que potencializa os elementos do território, numa relação dialógica com os vários atores que nele estabelecem suas múltiplas territorialidades. Neste ínterim, a comunidade local sente-se parte da gênese do turismo, nutrindo relação harmoniosa com o turista, numa tônica onde o território fomenta e é fomentado pelo setor do turismo. 


\section{Considerações finais}

As análises teóricas e as experiências relatadas remetem ao entendimento de que é factível a prática do turismo de uma forma integrada, acolhedora e comprometida com o desenvolvimento dos territórios onde está inserido. Necessitase de uma rica relação dialógica e solidária entre os vários agentes de todas as ações que compõem a atividade do turismo (incluindo as comunidades locais).

Reconhecer a existência do território com possibilidades de ações constitutivas a uma nova atividade, bem como as dinâmicas sob as quais os territórios são (re)criados, são condições basilares para que o turismo de fato seja planejado e programado para o fomento do desenvolvimento das localidades.

As alternativas de desenvolvimento propostas a partir do turismo de base local indicam que o turismo rural pode ser importante fonte de renda secundária para o grupo de camponeses que demonstraram interesses nessa atividade. $O$ êxito dependerá de esforços coletivos, mas fundamentalmente do empoderamento da Associação local animada no sentido de ser protagonista dos destinos das famílias que lutam pela permanência no campo. A Incubadora Tecnológica de Cooperativas Populares do Pantanal e da Fronteira se constitui num importante vetor do desenvolvimento territorial para os camponeses do assentamento 72 , com capacidade de articulação de parcerias para implementação do turismo rural na localidade.

\section{Referências Bibliográficas}

BARRETO, M. O imprescindível aporte das ciências sociais para o planejamento e a compreensão do turismo. Horizontes antropológicos, Porto Alegre, 2003, 9 (20), p. 15-29.

BRASIL. Manual de municipalização do turismo. Brasília: Ministério do Turismo; Embratur, 1998.

CAMPANHOLA, C.; GRAZIANO DA SILVA, J. Diretrizes de Políticas Públicas para o novo rural brasileiro: incorporando a noção de desenvolvimento local. In: CAMPANHOLA, C.; GRAZIANO DA SILVA, J. (Eds.). O novo rural brasileiro: políticas públicas. Jaguariúna: Embrapa Meio Ambiente, 2000, p. 61-92.

CANDIOTTO, L.Z.P. Uma reflexão sobre ciência e conceitos: o território na geografia. In: RIBAS, A.D.; SPOSITO, E.S.; SAQUET, M.A. Território e desenvolvimento: diferentes abordagens. Francisco Beltrão: Unioeste, 2004,p. 67-86.

CARNEIRO, M.J. Ruralidade: novas identidades em construção. Estudos Sociedade e Agricultura (UFRJ), Rio de Janeiro, 11, p. 53-75, 1998.

CORIOLANO, L.N.M.T. O turismo nos discursos, nas políticas e no combate à pobreza. São Paulo: Annablume, 2001.

COSTA, E.A. A experiência de desenvolvimento rural sustentável no assentamento 72, Ladário - MS. In: ARAUJO, A.P.C.; VARGAS, I.A. (Orgs.). Dinâmicas do rural contemporâneo. Campo Grande: Ed. UFMS, v. 1, 2014, p. 143-162. 
COSTA, E.A.; ZARATE, S.S.; MACEDO, H.A. Principiar do desenvolvimento territorial no assentamento rural 72, em Ladário-MS, Brasil. In: SAQUET, M.A.; DANSERO, E.; CANDIOTTO, L.Z.P. (Orgs). Geografia da e para a cooperação ao desenvolvimento territorial: experiências brasileiras e italianas. São Paulo: Outras Expressões, 2012, p.125-145.

FIGUEIREDO, N.P.; COSTA, E.A.; PAULA, B.L. Os elementos do espaço turístico da fronteira Brasil-Bolívia. Ra'e ga, 21, Curitiba, 2011, p.105-138.

GEHLEN, I. Centralidade do trabalho e exclusão identitária no meio rural. Revista Sociedade em Debate, Pelotas, 2003, p. 287-300.

GOTTMANN, J. The significance of territory. Charlottesville: University Press of Virginia, 1973.

IRVING, M.A. Turismo, ética e educação ambiental: novos paradigmas em planejamento. In IRVING, M. A.; AZEVEDO, J. Turismo: o desafio da sustentabilidade. São Paulo, SP: Futura, 2002, p. 17-34.

ISSA, Y.S.M.M. Produção do turismo e sítios simbólicos de pertencimento: inserção da comunidade local como fator de hospitalidade. V SEMINTUR, 2008, Caxias do Sul/RS. Anais... V Seminário de Pesquisa em Turismo do MERCOSUL, 2008.

MATO GROSSO DO SUL. Plano de recuperação do assentamento 72. Campo Grande: AGRAER/INCRA, 2008.

MENDONÇA, T.C.M.; MORAES, E.A.; COSTA, M.A.M. Turismo e pesca nas Reservas Extrativistas Marinhas de Arraial do Cabo (RJ) e da Prainha do Canto Verde (CE): possibilidades e limites de complementaridade. Caderno Virtual de Turismo. Rio de Janeiro, 2013, p. 372-390, 2013.

MENDONÇA, T.C.M. Turismo e participação comunitária: Prainha do Canto Verde, a 'canoa' que não quebrou e a 'fonte' que não secou? Rio de Janeiro: Universidade Federal do Rio de Janeiro (UFRJ); Programa EICOS/IP. Dissertação (Mestrado em Psicossociologia de Comunidade e Ecologia Social), 2004.

PERKINS, D.D.; ZIMMERMAN, M.A. Empowerment meets narrative: listening to stories and creating settings. American Journal of Community Psicology, 23, (5), 1995, p. 569-579.

PROENÇA, R.P.C. Alimentação e globalização: algumas reflexões. Cienc. Cult., São Paulo, 62 (4), 2010, p.43-47.

PUGLIESI, A.A.; CUNHA, F.B. A gastronomia no Paraná. In: HAMERSCHMIDT, I.; OLIVEIRA, S. (Orgs.). Alimentação Saudável e Sustentabilidade Ambiental nas Escolas do Paraná. Curitiba: Instituto Emater, 2014, p.73-96.

RAFFESTIN, C. Por uma geografia do poder. São Paulo: Ática,1993.

SANTOS, M. Espaço e método. São Paulo: Edusp, 1985.

SCHNEIDER, S. Turismo em comunidades rurais: inclusão social por meio de atividades não agrícolas. In: BRASIL. Diálogos do turismo: uma viagem de inclusão. Brasília: Ministério do Turismo, 2006, p.264-293.

SOUZA, M.J.L. O território: sobre espaço e poder; autonomia e desenvolvimento. In CASTRO, I.E.; GOMES, P.C.C.; CORRÊA, R.L. (Orgs.). Geografia: conceitos e temas. Rio de Janeiro: Bertrand Brasil, 2001, p. 77-116.

ZIMMERMAN, M.A. Psychological empowerment: Issues and illustrations. American Journal of Community Psychology, 1995, p. 581-599. 


\section{Agradecimentos}

O trabalho é resultado parcial dos projetos de pesquisa: "Alternativas para o desenvolvimento territorial rural do assentamento 72 em Ladário-MS, na região do Pantanal", com recursos do CNPq e, "Sistemas agroecológicos na fronteira BrasilBolívia: estudo comparativo das alternativas induzidas no assentamento 72, em Ladário-MS, com as práticas do assentamento Rosely Nunes, em Mirassol D' Oeste-MT", com recursos do MCT/CNPq e FUNDECT/MS. Essa pesquisa deve seu reconhecimento à importante parceria com a Embrapa Pantanal, Sebrae-MS, Senar, Associação dos Trabalhadores Rurais do Assentamento 72 e da Prefeitura Municipal de Ladário-MS. Agradecemos à Ramona Trindade Ramos Dias pela revisão do texto.

Éder Damião Goes Kukiel: Universidade Federal de Mato Grosso do Sul, Corumbá, MS, Brasil.

E-mail: kukielgeografia@gmail.com

Link para o currículo Lattes: http://lattes.cnpq.br/5486496306025518

Edgar Aparecido da Costa: Universidade Federal de Mato Grosso do Sul, Corumbá, MS, Brasil.

E-mail: edgarac10@gmail.com

Link para o currículo Lattes: http://lattes.cnpq.br/3166411825044548

Milton Augusto Pasquotto Mariani: Universidade Federal de Mato Grosso do Sul, Campo Grande, MS, Brasil.

E-mail: miltmari@terra.com.br

Link para o currículo Lattes: http://lattes.cnpq.br/0935409945176042

Data de submissão: 08 de outubro de 2015

Data de recebimento de correções: 25 de novembro de 2016

Data do aceite: 25 de novembro de 2016

Avaliado anonimamente 